\title{
Inverted Meckel's Diverticulum with Ectopic Pancreatic Tissue as a Source of Severe Gastrointestinal Bleeding
}

\author{
Marcela Kopáčová • Ladislav Vykouřil • \\ Zdeněk Vacek • Věra Tyčová • Jolana Bártová • \\ Stanislav Rejchrt • Jan Bureš
}

Received: 8 February 2009 / Accepted: 18 February 2009/Published online: 10 March 2009

(C) The Author(s) 2009. This article is published with open access at Springerlink.com

\begin{abstract}
Introduction Meckel's diverticulum is the most common congenital anomaly of the gastrointestinal tract. Authors present a 67-year-old woman treated for iron deficiency anemia for the past 5 years. Suddenly, her disease was presented with painless severe gastrointestinal bleeding (fresh melena). Inverted Meckel's diverticulum with ectopic pancreatic tissue as a source of severe gastrointestinal bleeding was diagnosed by intraoperative enteroscopy.

Conclusion A combination of inversion of Meckel's diverticulum with ectopic pancreatic tissue is extremely rare, particularly in elderly patient. Capsule endoscopy, double balloon enteroscopy, and ultimately intraoperative enteroscopy may be helpful in timely diagnosis.
\end{abstract}

Keywords Meckel's diverticulum · Intussusception · Intraoperative enteroscopy $\cdot$ Ectopic pancreas

\footnotetext{
M. Kopáčová $(\varangle) \cdot J$. Bártová $\cdot S$. Rejchrt · J. Bureš

Second Department of Internal Medicine,

Faculty of Medicine at Hradec Králové,

Charles University in Praha,

University Teaching Hospital,

Sokolská 581,

50005 Hradec Králové, Czech Republic

e-mail: kopacmar@fnhk.cz

L. Vykouřil

Department of Surgery, Faculty of Medicine at Hradec Králové, Charles University in Praha, University Teaching Hospital,

Hradec Králové, Czech Republic

Z. Vacek

Department of Radiology,

Faculty of Medicine at Hradec Králové,

Charles University in Praha, University Teaching Hospital,

Hradec Králové, Czech Republic

V. Tyčová

The Fingerland Department of Pathology,

Faculty of Medicine at Hradec Králové,

Charles University in Praha,

University Teaching Hospital,

Hradec Králové, Czech Republic

\section{Introduction}

Meckel's diverticulum is the most common congenital anomaly of the gastrointestinal tract $(1-3 \%$ of the population in autopsy studies, twice as more frequently found in males). It derives from incomplete obliteration of the yolk stalk (omphalo-mesenteric duct). Meckel's diverticulum is a true diverticulum with all layers of the intestinal wall present. It arises from the antimesenterial border, located usually $100 \mathrm{~cm}$ proximal to the ileo-cecal valve, has its own mesentery and blood supply from a terminal branch of the superior mesenteric artery. Diverticula that do not contain normal ileal mucosa may harbor ectopic glandular tissue: gastric $(\sim 50 \%)$, duodenal Brunner's glands, pancreatic acinar tissue, colonic mucosa, endometrium, hepatobiliary tissue, or their combination. Meckel's diverticulum is usually asymptomatic, only about $2 \%$ develop a complication over the course of their life. Sixty percent of patients having complications are younger than 2 years, painless bleeding (from peptic ulceration in ectopic gastric mucosa) is the most common. Helicobacter pylori may colonize the gastric mucosa of Meckel's diverticulum, but it likely plays no role in bleeding diverticula. Other complications of Meckel's diverticulum comprise diverticulitis, iron deficiency anemia, intestinal obstruction, and perforation (from foreign bodies, diverticulitis, peptic ulceration, or blunt 
abdominal trauma). A longer diverticulum (length $>2 \mathrm{~cm}$ ) is associated with a higher risk of complications. Bacterial overgrowth, intussusception, volvulus, strangulation, Littre's herniation, phytobezoars, formation of enteroliths, and malignant transformation (carcinoid, adenocarcinoma, or leiomyosarcoma) are all very unusual. ${ }^{1-3}$

We report an unusual case of severe gastrointestinal bleeding from inverted Meckel's diverticulum with ectopic pancreatic tissue in an elderly patient.

\section{Clinical History and Histological Findings}

A 67-year-old woman was treated for iron deficiency anemia for the past 5 years. Suddenly, her disease was presented with painless severe gastrointestinal bleeding (fresh melena) elsewhere. Bleeding required $6 \mathrm{U}$ of blood within $24 \mathrm{~h}$. The source of the bleeding was not identified either by gastroscopy or colonoscopy, and the patient was referred to our department as a case of acute obscure overt bleeding. Enteroclysis revealed a large polyp $(8 \mathrm{~cm}$ in length) $80 \mathrm{~cm}$ proximal to the ileo-cecal valve and nearly obstructing the entire intestinal lumen (Fig. 1). Intraoperative enteroscopy was carried out as the next step because of supposed multiple small bowel polyps. Surprisingly, an inverted Meckel's diverticulum was found with three ulcers; one of them with adhering blood clot (Fig. 2). An area of whitish tissue was discovered at the tip of the intussusceptum after its disimpaction (Fig. 3). The surgeon decided to resect the diverticulum together with $10 \mathrm{~cm}$ of the adjacent ileum (Fig. 4). Histology confirmed Meckel's diverticulum with ulcers (Fig. 5). A pancreatic tissue was identified in the whitish tissue by histology. Heterotopic pancreatic tissue was fully formed with acinar tissue, islets, and draining duct (Fig. 6). There was no gastric mucosa in

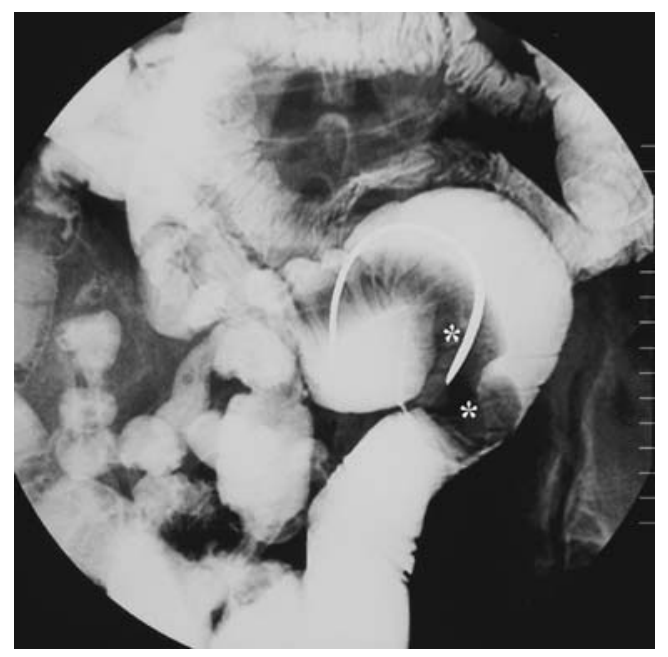

Figure 1 Enteroclysis. Smoothly marginated intraluminal mass in the ileum simulated an intraluminal polyp (asterisk).

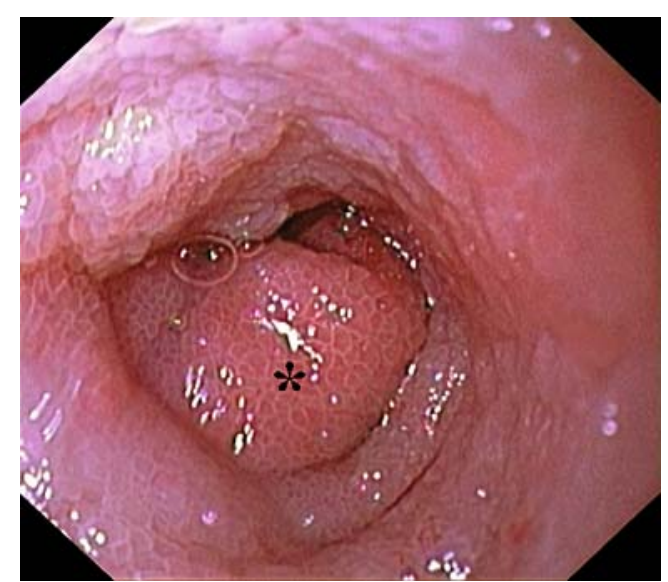

Figure 2 Intraoperative enteroscopy. Obstruction of the ileum caused by inverted Meckel's diverticulum. Swollen mucosa of the diverticulum is nicely visible (asterisk).

the diverticulum. The postoperative course was uneventful, and the patient was released from the hospital 10 days later.

\section{Discussion}

Meckel's diverticulum is the most common congenital anomaly of the gastrointestinal tract ( $1-3 \%$ of the population in autopsy studies, twice as more frequently found in males). Sixty percent of patients having complications are younger than 2 years; painless bleeding (from peptic ulceration in ectopic gastric mucosa) is the most common. ${ }^{1}$

We present a remarkable case of inverted Meckel's diverticulum as a quite rare cause of painless severe acute gastrointestinal bleeding. We have found only 15 reports of inverted diverticulum ${ }^{4,5}$ and only a few cases similar to ours, ${ }^{6-8}$ but none of them was described in elderly patients. Other cases presented with iron deficiency anemia, diarrhea and vomiting, strangulated intestinal obstruction, intussusception,

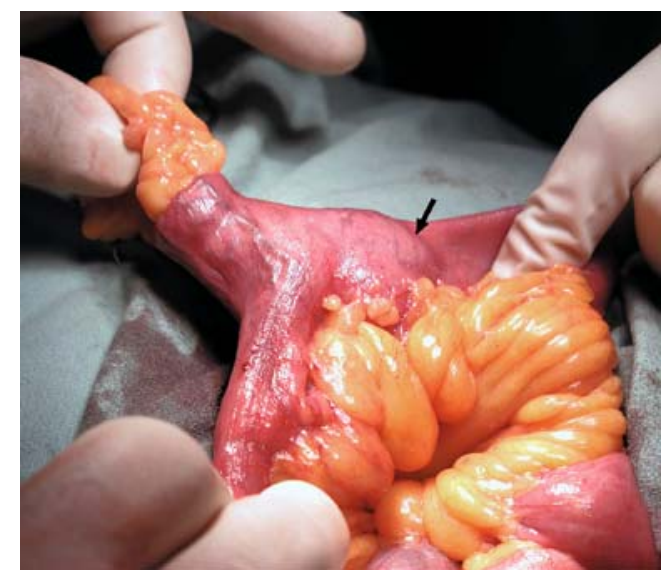

Figure 3 Surgical field - view of open abdominal cavity. Extraction of the Meckel's diverticulum; large part of it is still inverted (arrow). 


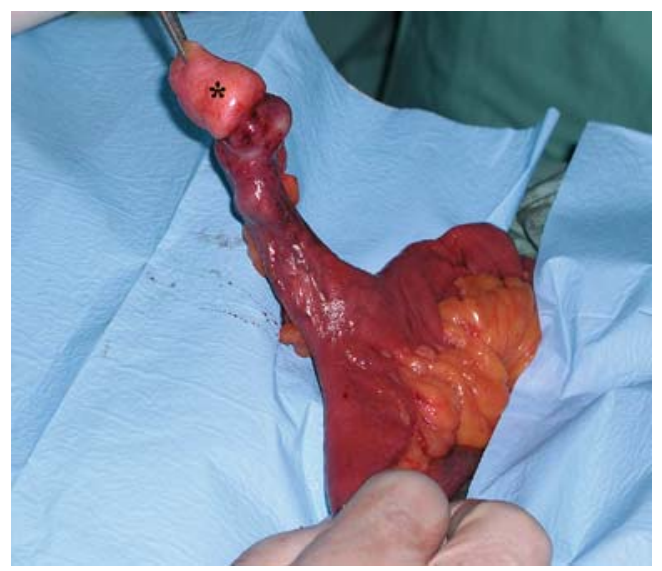

Figure 4 Surgical field-view of open abdominal cavity. Meckel's diverticulum after extraction is seen. White tissue on the tip (asterisk) is the heterotopic pancreas.

mimicking Crohn's disease or tumor. ${ }^{5}$ Once inverted, the diverticulum may serve as the site of intestinal obstruction or lead point for an ileo-ileal or ileo-colic intussusception., ${ }^{6,8}$ Ectopic pancreatic tissue is a rare condition. Heterotopic pancreas is a rare cause of intussusception. It is supposed that this lesion is of vitellointestinal tract origin, conceptually similar to a Meckel's diverticulum but without a diverticulum as such. Heterotopic pancreatic tissue occurring alone is more common in the proximal small intestine, duodenum, and stomach than in the ileum, and it is often asymptomatic. ${ }^{6}$

More than 2,800 papers were published on Meckel's diverticulum over the past five decades (according to a PubMed search). However, most publications have been either small series or case reports. The largest series was published by Park et al. as the Mayo Clinic experience with 1,476 patients (collected from 1950 to 2002 ). ${ }^{3}$ Only $16 \%$ were symptomatic. Among 180 adult patients, bleeding (69

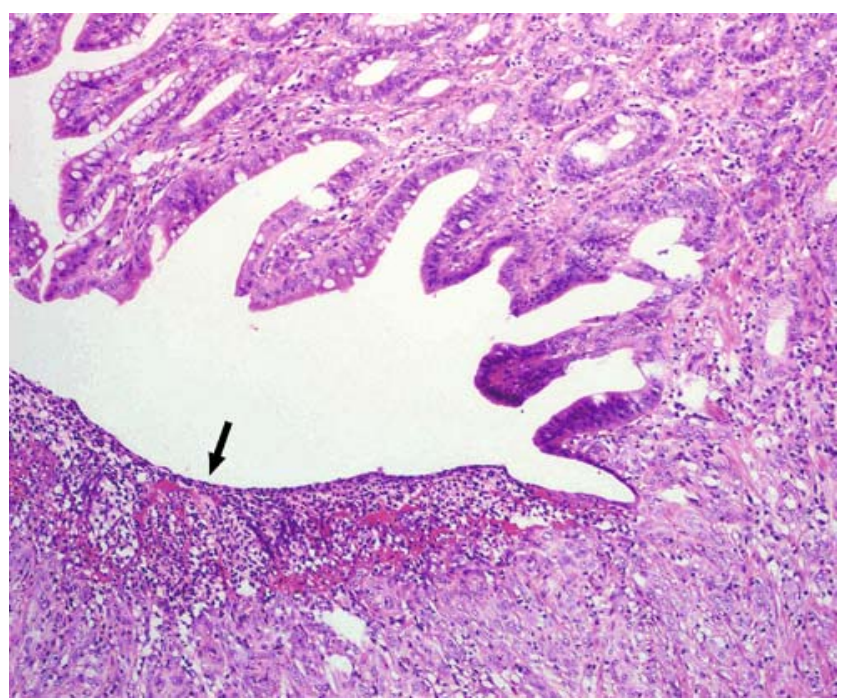

Figure 5 Ulcer of the Meckel's diverticulum (arrow). Hematoxylin-eosin.

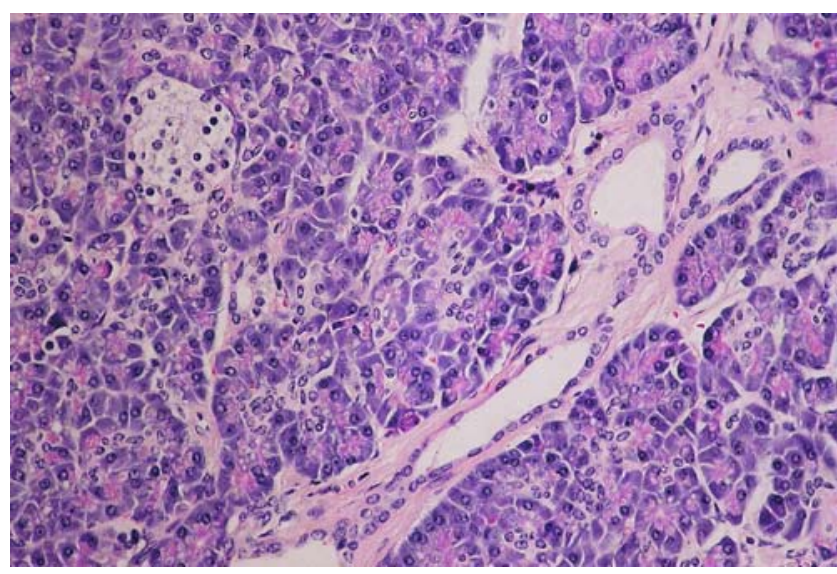

Figure 6 Ectopic pancreatic tissue. Hematoxylin-eosin.

out of $180 ; 38 \%$ ), obstruction (61 out of $180 ; 34 \%$ ), and diverticulitis (50 out of $180 ; 28 \%$ ) were the most common complications. The authors do not mention any case of inverted Meckel's diverticulum. ${ }^{3}$

A ${ }^{99} \mathrm{~m}_{\text {technetium pertechnate scintigraphy is a principal }}$ investigation, it detects ectopic gastric mucosa in Meckel's diverticulum, pretreatment with pentagastrin or $\mathrm{H}_{2}$-receptor antagonists reduces false negative results. Pentagastrin accelerates $\mathrm{Tc}$ uptake, and an $\mathrm{H}_{2}$-receptor antagonist decreases $\mathrm{Tc}$ release by the gastric mucosa. ${ }^{1}$ However, only one half of Meckel's diverticula harbor gastric mucosa. Other diagnostic tools comprise [computed tomography (CT)/magnetic resonance] enteroclysis, intraoperative enteroscopy, ${ }^{9}$ Doppler ultrasonography,${ }^{10}$ angiography, and recently wireless capsule endoscopy ${ }^{11,12}$ and double balloon enteroscopy. ${ }^{5,13}$

Abdominal radiographic findings are most often nonspecific in these cases unless the patients have intestinal obstruction or intussusception. Enteroclysis shows an elongated, smoothly marginated intraluminal mass that parallels the long axis of the intestine and frequently has a bulbous or club-like tip. It may also appear as a pedunculated intraluminal polyp. ${ }^{4}$ CT characteristically shows the inverted diverticulum as a central core of fat attenuation surrounded by a collar of soft-tissue attenuation. At sonography, the inverted diverticulum has a target-like appearance with central hyperechogenicity from the core of mesenteric fat or a double target appearance when the entire section of the small intestine containing the inverted diverticulum is visualized. Doppler sonography may reveal anomalous vessels. ${ }^{10}$ The differential diagnosis for an elongated tubular filling defect produced by an inverted Meckel's diverticulum on barium images of the small intestine includes elongated pedunculated polyps such as Peutz-Jeghers syndrome. ${ }^{9}$ The principal differential diagnosis for an inverted Meckel's diverticulum on $\mathrm{CT}$ scans is a lipoma. Intestinal lipomas have fat attenuation at $\mathrm{CT}$, but they lack the collar of soft-tissue attenuation that is seen in inverted Meckel's 
diverticulum. ${ }^{14}$ When the vitalline artery is seen in the ilea lumen on angiography, inverted Meckel's diverticulum should be considered.

In our particular case, inverted Meckel's diverticulum also mimicked elongated pedunculated polyp on enteroclysis. It was not until intraoperative enteroscopy that the correct diagnosis was determined. Surgical resection in the same anesthesia provided a final solution.

\section{Conclusions}

Meckel's diverticulum is the most common anomaly of the gastrointestinal tract. However, most of them are asymptomatic lifelong. Clinical symptoms arise from complications of the diverticulum which are very rare in elderly people. Preoperative diagnosis of a complicated Meckel's diverticulum may be challenging because clinical and imaging features overlap with those of other causes of acute abdomen. In case of severe painless acute obscure overt bleeding, Meckel's diverticulum should be considered even in elderly patients. A combination of inversion of Meckel's diverticulum with ectopic pancreatic tissue is extremely rare. Capsule endoscopy, double balloon enteroscopy, and ultimately intraoperative enteroscopy may be helpful in timely diagnosis.

Acknowledgements The study was supported by the research project: MZO 00179906 from the Ministry of Health, Czech Republic.

Open Access This article is distributed under the terms of the Creative Commons Attribution Noncommercial License which permits any noncommercial use, distribution, and reproduction in any medium, provided the original author(s) and source are credited.

\section{References}

1. Dumper J, Mackenzie S, Mitchell P, et al. Complications of Meckel's diverticula in adults. Can J Surg 2006;49:353-357.
2. Kazemi K, Jalaeian H, Fattahi MR, et al. Ruptured Meckel's mesodiverticulum and Meckel's diverticulum following blunt abdominal trauma. Med Princ Pract 2008;17:161-163. doi:10.1159/000112973.

3. Park JJ, Wolff BG, Tollefson MK, et al. Meckel diverticulum: the Mayo Clinic experience with 1476 patients $(1950-2002)$. Ann Surg 2005;241:529-533. doi:10.1097/01.sla.0000154270. $14308.5 f$

4. Fetterman LE. Meckel's diverticulum radiographically appearing as a polyp (inverted). Br J Radiol 1968;41:940-941.

5. Chen CM, Chao CC, Chiu HH. Meckel's diverticulum with recurrent bleeding diagnosed by double-balloon enteroscopy. Clin Gastroenterol Hepatol 2007;5:e40-e41. doi:10.1016/j.cgh.2007. 07.016.

6. Abel R, Keen CHE, Bingham JB, Maynard J, Agrawal MR, Ramachandra S. Heterotopic Pancreas as Lead Point in Intussusception: New Variant of Vitellointestinal Tract Malformation. Ped Dev Path 1999;2:367-370. doi:10.1007/s1002 49900136.

7. Andrabi SI, Spence GM, Clements WB. Inversion of Meckel's diverticulum causing gastrointestinal bleeding and small bowel obstruction. Br J Hosp Med (Lond) 2007;68:442-443.

8. Cates JMM, Williams TL, Suriawinata AA. Intraductal papillary mucinous adenoma that arises from pancreatic heterotopia within a Meckel diverticulum. Arch Pathol Lab Med 2005;129: e67-e69.

9. Kopáčová M, Bureš J, Vykouřil J, et al. Intraoperative enteroscopy. Ten years' experience at a single tertiary centre. Surg Endosc 2007;21:1111-1116. doi:10.1007/s00464-006-9052-4.

10. Baldisserotto M, Maffazzoni DR, Dora MD. Sonographic findings of Meckel's diverticulitis in children. AJR Am J Roentgenol 2003; 180:425-428.

11. Ge ZZ, Chen HY, Gao YJ, et al. Clinical application of wireless capsule endoscopy in pediatric patients for suspected small bowel diseases. Eur J Pediatr 2007;166:825-829. doi:10.1007/s00431006-0331-9.

12. Moy L, Levine J. Wireless capsule endoscopy in the pediatric age group: experience and complications. J Pediatr Gastroenterol Nutr 2007;44:516-520. doi:10.1097/MPG.0b013e3180335548.

13. Botha FJH, Zuckerman M, Grobler SP. Meckel's diverticulum with heterotopic gastric mucosal polyps. In Mulder CJJ, ed. Atlas of Double Balloon Endoscopy. Munich: Medconnect, 2007, pp 38-39.

14. Keljo DJ, Squires RH. Anatomy and anomalies of the small and large intestines. In Feldman M, Scharschmidt BF, Sleisenger MH, eds. Sleisenger \& Fordtran's Gastrointestinal and Liver Disease, 6th ed. Philadelphia: WB Saunders, 1998, pp 1419-1436. 